\title{
Erratum to: CME Instructions: PET Measurement of Adenosine Stimulated Absolute Myocardial Blood Flow for Physiological Assessment of the Coronary Circulation
}

\author{
American Society of Nuclear Cardiology
}

\section{ERRATUM TO: J NUCL CARDIOL 2012;19:355-9 DOI 10.1007/S12350-012-9532-Y}

The Journal CME test for the CME Article entitled, "PET Measurement of Adenosine Stimulated Absolute Myocardial Blood Flow for Physiological Assessment of the Coronary Circulation' (March/ April 2012 issue, Volume 19, Number 2) contained an invalid assessment question, which thereby renders the test invalid. If you have taken this exam and passed, your CME credit remains intact. All individuals who took the original exam are encouraged to take the revised test over to assure an accurate assessment.

If you have taken this exam and failed, the failed exam is expunged and you are now able to retake the new version of the exam for credit.

We sincerely apologize for this inconvenience. A new exam has been created and can be found in this erratum.

The Journal CME article entitled, "PET Measurement of Adenosine Stimulated Absolute Myocardial Blood Flow for Physiological Assessment of the Coronary Circulation' published in the March/April 2012 issue can be accessed here at DOI: 10.1007/s12350011-9510-9.

\section{CME INSTRUCTIONS: PET MEASUREMENT \\ OF ADENOSINE STIMULATED ABSOLUTE MYOCARDIAL BLOOD FLOW FOR PHYSIOLOGICAL ASSESSMENT OF THE CORONARY CIRCULATION}

\section{STATEMENT OF NEED}

The following educational gaps have been identified to demonstrate need for this journal continuing education activity:

- Concerns related to radiation exposure, health care economics, and laboratory efficiency of SPECT and PET myocardial perfusion imaging (MPI) have generated considerable attention of late.

- Quantitative PET measurement of myocardial blood flow is capable of overcoming the limitations of SPECT MPI.

- Quantitative PET measurement of myocardial blood flow in conjunction with stress-only imaging may considerably reduce radiation dose as well as costs.

\section{TARGET AUDIENCE}

This activity is targeted at imaging professionals and is intended to provide the latest information on clinical practice and cutting-edge scientific advances in nuclear cardiology and cardiac imaging.

\section{OBJECTIVES}

After reading and reflecting upon an article in the Journal of Nuclear Cardiology, the learner should be able to:

- Describe the application of PET quantitative measurement of absolute myocardial blood flow in patients with ischemic heart disease.

- Describe the application of PET quantitative measurement of absolute myocardial blood flow in patients with heart failure.
The online version of the original article can be found under doi:10.1007/s12350-012-9532-y.

Reprint requests: American Society of Nuclear Cardiology, 4340 East West Hwy., Suite 1120, Bethesda, MD 20814; info@asnc.org. J Nucl Cardiol 2012;19:1086-91.

$1071-3581 / \$ 34.00$

Copyright $(2) 2012$ American Society of Nuclear Cardiology.

doi:10.1007/s12350-012-9608-8 
- Discuss the value and potential limitations of performing stress-only imaging in the clinical context.

\section{ACCREDITATION AND CONTINUING EDUCATION CREDIT}

\section{Physicians}

The American Society of Nuclear Cardiology is accredited by the Accreditation Council for Continuing Medical Education to provide continuing medical education for physicians.

The American Society of Nuclear Cardiology designates this Journal-based CME activity for a maximum of 1 AMA PRA Category 1 Credits $^{\mathrm{TM}}$. Physicians should only claim credit commensurate with the extent of their participation in the activity.

\section{Technologists}

The American Society of Nuclear Cardiology is a recognized provider of continuing education credit for technologists. ASNC's Continuing Education (ACE) credit is accepted by both NMTCB and ARRT. This Journal-based activity has been approved for a maximum of 1 ACE credits for Technologists.

\section{FACULTY DISCLOSURE}

As an accredited provider of the Accreditation Council for Continuing Medical Education (ACCME), The American Society of Nuclear Cardiology (ASNC) adheres to the ACCME's 2008 Standards for Commercial Support. In compliance with these standards, it is ASNC's policy to ensure balance, independence, objectivity, and scientific merit in all of its educational activities through the disclosure of relevant relationship with commercial companies. The financial interest or relationships requiring disclosure are outlined in ASNC's CME Conflict of Interest Policy. All authors involved with this activity are required to disclose any relevant financial relationships.

The following authors reported no financial relationships: Henry Gewirtz, MD.

The following members of the JNC Editorial Staff reported no financial relationships: George A. Beller, MD, FASNC and Wendy Passerell.

The following ASNC staff and article reviewers who were involved in the planning and development of this activity reported no financial relationships: Sharmila Dorbala, MD; Beth Hodge; Saurabh Malhotra, MD; Nancy McDonald, NCT, RT, CNMT.
The following article reviewer who was involved in the planning and development of this activity reported a financial relationship: Jersey Chen, MD: Grant Support, Lantheus Medical Imaging.

\section{OFF LABEL USE}

Articles may include discussion of drugs or devices, or uses of drugs or devices, that have not been approved by the Food and Drug Administration (FDA) or have been approved by the FDA for specific uses only. The FDA has stated that it is the responsibility of the physician to determine the FDA clearance status of each drug or device he or she wishes to use in clinical practice. ASNC is committed to the free exchange of medical education. Inclusion of any discussion in this program, including discussion on off-label uses, does not imply an endorsement by ASNC of the uses, products or techniques presented.

\section{CONTINUING EDUCATION TERM OF APPROVAL}

Release Date: March 15, 2012

Date of Last Review: February 13, 2012

Expiration Date: March 14, 2013

\section{METHOD OF PARTICIPATION}

To receive a statement of credit, participants must successfully complete the quiz and evaluation questions after reading and reflecting on the article. The participant selects the single most appropriate answer for each question. A score of $80 \%$ or higher is needed to pass the quiz. If less than $80 \%$ of the questions were correct, the participant will be notified and may resubmit the quiz with modified answers up to three times. Tests will be graded by ASNC staff members.

Estimated time of completion is one hour.

Send your completed post-test and evaluation by mail, fax, or e-mail to:

\author{
American Society of Nuclear Cardiology \\ Attn: JNC Continuing Education \\ 4340 East-West Highway, Suite 1120 \\ Bethesda, MD 20814-4578 \\ Fax: (301) 215-7113 \\ E-mail: JournalCredit@asnc.org
}

\section{PROCESSING FEES}

ASNC members may claim continuing education credits at no charge. Non-members will be charged $\$ 25$ 
per activity. Please fill out the payment area included on the evaluation form.

\section{ACKNOWLEDGEMENT OF COMMERCIAL SUPPORT}

This activity is not supported by commercial support.

\section{PRIVACY \& CONFIDENTIALITY STATEMENT}

ASNC will record learner's personal information as provided on CME evaluations to allow for issuance and tracking of CME certificates. ASNC may also track aggregate responses to questions in activities and evaluations and use these data to inform the ongoing evaluation and improvement of its CME program. No individual performance data or any other personal information collected from evaluations will be shared with third parties.

For questions regarding CME content or obtaining CME credit, please contact ASNC at 301.215.7575 or info@asnc.org. 


\section{REVISED CME QUIZ \& REGISTRATION FORM}

In order to earn CME credit for this journal activity, you must read the article and successfully pass the posttest. A passing grade of $80 \%$ is required to earn credit.

CME/ACE certificates will be sent within ten (10) business days.

\section{Please mail or fax this form to:}

American Society of Nuclear Cardiology

Attn: JNC CME

4340 East-West Highway, Suite 1120

Bethesda, MD 20814

Fax: (301) 215-7113

Email: Journalcredit@asnc.org

Please circle one response per question.

\section{CME QUIZ - REVISED}

1. A clinical scenario in which absolute vasodilator myocardial blood flow (MBF) measurement alone without rest MBF could be disadvantageous is:
a. Diffuse narrowing of epicardial conduit vessels
b. Coronary steal
c. Multivessel coronary artery disease

2. Which of the following are the clinical limitations of PET measurement of adenosine stimulated myocardial blood flow and coronary flow reserve
a. Greater radiation exposure
b. Longer scan times
c. Challenging to differentiate between multivessel from microvessel coronary artery disease without the knowledge of patients' coronary anatomy.
d. All of the above

3. Factors that influence rest myocardial blood flow include
a. Heart rate
b. Arterial blood pressure
c. Myocardial contractility
d. All of the above

4. The following statements about assessment of fractional flow reserve (FFR) assessment by angiography and coronary flow reserve (CFR) by PET are true

a. CFR integrates the flow across all three coronary vascular distributions b. A single FFR integrates the flow across all three coronary vascular distributions

c. A fractional flow reserve of $<0.8$ is considered abnormal

d. A stress myocardial blood flow value of $2.5 \mathrm{ml} /$ $\mathrm{gm} / \mathrm{min}$ with adenosine or dobutamine would be abnormal

e. A and C are correct

f. All of the above

5. The degree of epicardial coronary disease is accurately assessed by quantitative PET using

a. Myocardial blood flow reserve (ratio of vasodilator MBF to rest MBF)

b. Myocardial blood flow during peak vasodilator stress

c. Myocardial blood flow at rest

d. Absolute difference between myocardial blood flow obtained at vasodilator stress and rest

6. Which of the following is an FDA approved PET radiotracer that can be used for assessing absolute myocardial blood flow
a. $13 \mathrm{~N}$-ammonia
b. $18 \mathrm{~F}$-flurpiridaz
c. $11 \mathrm{C}$-acetate
d. $15 \mathrm{O}$-water

7. Quantitative PET and absolute myocardial blood flow imaging may be useful for the clinical management of patients with:
a. Amyloidosis
b. Syndrome X (microvascular dysfunction)
c. Coronary vasospasm
d. Takasubo stress cardiomyopathy

8. The potential benefit from using quantitative PET for assessing cardiac transplant patients is:

a. Identifying individuals with transplant rejection

b. Detecting early coronary artery vasculopathy

c. A and B

See CME article, pp. 347-354 (Volume 19, Number 2, March/April 2012)

The Journal CME article entitled, "PET Measurement of Adenosine Stimulated Absolute Myocardial Blood Flow for Physiological Assessment of the Coronary Circulation" published in the March/April 2012 issue can be accessed here at DOI: 10.1007/s12350011-9510-9. 


\section{CE Registration Form}

In order to process the post-test, please complete the registration information below. A CME/ACE certificate will be issued once the test is processed.

\section{PLEASE PRINT}

I am requesting: $\square$ CME $\square$ ACE

\begin{tabular}{lll}
\hline Last Name & First Name & Degree
\end{tabular}

Phone Number

Fax Number

E-mail

Member ID (If Applicable)

\section{BILLING}

$\square$ Member (\$0 fee) $\square$ Non-Member (\$25 fee)

Non-Members please fill out the information below:

Type of Card: $\square$ Visa $\square$ MasterCard $\square$ Amex

Name on Card

Card Number

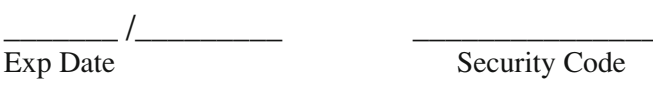

Billing Address

\begin{tabular}{lll}
\hline City & State & Zip Code
\end{tabular}

Cardholder Signature 


\section{EVALUATION FORM}

PET Measurement of Adenosine Stimulated Absolute Myocardial Blood Flow for Physiological Assessment of the Coronary Circulation

The American Society of Nuclear Cardiology appreciates and values your opinions. In order to assist us in evaluating the effectiveness of this program and to make recommendations for future online educational offerings, please take a moment to complete this evaluation form.

Directions: Please select your responses to complete this evaluation form.

Your comments and suggestions will aid in planning future activities.

Please rate how strongly you agree or disagree with these statements:
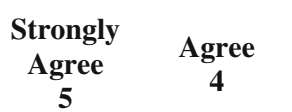

1. The following stated learning objectives were achieved:

\begin{tabular}{|c|c|c|c|c|c|c|}
\hline $\begin{array}{l}\text { Describe the application of PET quantitative measurement of } \\
\text { absolute myocardial blood flow in patients with ischemic } \\
\text { heart disease. }\end{array}$ & O & O & & O & O & 0 \\
\hline $\begin{array}{l}\text { Describe the application of PET quantitative measurement of } \\
\text { absolute myocardial blood flow in patients with heart failure. }\end{array}$ & O & O & & O & O & O \\
\hline $\begin{array}{l}\text { Discuss the value and potential limitations of performing } \\
\text { stress-only imaging in the clinical context. }\end{array}$ & O & O & & O & O & O \\
\hline 2. Disclosure was made to the participants & O & O & & O & O & O \\
\hline $\begin{array}{l}\text { 3. Did you perceive any commercial bias throughout the article? If } \\
\text { so, please list the author(s) and the perceived bias(es): }\end{array}$ & & & & & & \\
\hline $\begin{array}{l}\text { 4. Will any of the topics presented in the article improve the quality } \\
\text { of care in your practice? If so, in what way? }\end{array}$ & & & & & & \\
\hline $\begin{array}{l}\text { 5. Do you feel future activities on this subject matter are necessary } \\
\text { or important to your practice? }\end{array}$ & O & Yes & O & No & & \\
\hline 6. Please list any comments/suggestions for future activities: & & & & & & \\
\hline
\end{tabular}

